\title{
PENGEMBANGAN MEDIA PEMBELAJARAN MULTIMETER BERBASIS CD INTERAKTIF PADA MATA PELAJARAN DASAR LISTRIK DAN ELEKTRONIKA DI SMK NEGERI 3 SINGARAJA
}

\author{
B. G. A. Guna Suprapta ${ }^{1}$, G.R. A. Adiarta ${ }^{2}$, N. Santiyadnya ${ }^{3}$ \\ ${ }_{1,2,3}$ Prodi Pendidikan Teknik Elektro, Universitas Pendidikan Ganesha, Singaraja \\ e-mail: adigunasuprapta@gmail.com,agus.adiarta@undiksha.ac.id, santiyadnya@undiksha.ac.id
}

\begin{abstract}
Abstrak
Penelitian ini bertujuan untuk mengetahui 1) desain media pembelajaran multimeter berbasis CD interaktif, 2) tingkat kelayakan media pembelajaran multimeter berbasis CD interaktif 3) respon siswa setelah menggunakan media pembelajaran multimeter berbasis CD interaktif . Penelitian ini merupakan jenis Research and Development ( $R$ \& $D$ ) dan pengukuran tingkat kelayakan media menggunakan skala Linkert. Penelitian ini dilakukan pada siswa kelas X TAV 2 di SMK Negeri 3 Singaraja. Hasil penelitian terhadap media didapatkan: 1) media pembelajaran multimeter berbasis CD interaktif dapat dibuat, 2) persentase tingkat kelayakan media dari validator media $95,71 \%$ dengan kualifikasi sangat layak dan persentase tingkat kelayakan media dari validator materi $98,57 \%$ dengan dengan kualifikasi sangat layak, 3) mendapat respon siswa dengan kualifikasi sangat baik yaitu mendapat persentase respon siswa dalam kelompok kecil 89,07\% dengan kualifikasi sangat baik dan persentase respon siswa dalam kelompok besar $92,93 \%$ dengan kualifikasi sangat baik. Berdasarkan hasil analisis, media pembelajaran multimeter berbasis CD interaktif pada mata pelajaran Dasar Listrik dan Elektronika dapat digunakan sebagai media pembelajaran untuk siswa kelas X TAV di SMK Negeri 3 Singaraja.
\end{abstract}

Kata kunci: Media pembelajaran, CD interaktif, Dasar Listrik dan Elektronika

\begin{abstract}
This research aims to find out 1) the design of interactive $C D$-based multimeter learning media, 2) the feasibility level of interactive $C D$-based multimeter learning media 3) student responses after using interactive CD-based multimeter learning media. This research was a type of Research and Development $(R \& D)$ and measurement of the feasibility level for media using the Linkert scale. This research was conducted on tenth grade (X) TAV 2 students at Singaraja State Vocational High School. The results of the research on the media were obtained: 1) interactive CD-based multimeter learning media can be made, 2) the percentage level of media feasibility from the media validator is $95.71 \%$ with very feasible qualifications and the percentage level of media feasibility from the material validator is $98.57 \%$ with very feasible qualifications, 3) getting a response from students with very good qualifications, that is getting the percentage of student responses in small groups is $89.07 \%$ with very good qualifications and the percentage of students responses in large groups is $92.93 \%$ with very good qualifications. Based on the results of the analysis, interactive $C D$-based multimeter learning media on Basic Electrical and Electronics subjects can be used as learning media for tenth grade $(X)$ TAV students at Singaraja State Vocational High School 3.
\end{abstract}

Keywords: Learning media, interactive $C D$, Basic Electrical and Electronics

\section{Pendahuluan}

Pendidikan seringkali diartikan dan dimaknai orang secara beragam, bergantung pada sudut pandang masing-masing dan teori yang digunakan. Terjadinya perbedaan penafsiran pendidikan dalam konteks akademik merupakan sesuatu yang lumrah, bahkan dapat semakin memperkaya khazanah berpikir manusia dan bermanfaat untuk pengembangan teori itu sendiri. Tetapi untuk kepentingan kebijakan nasional, seyogianya pendidikan dapat dirumuskan secara jelas dan mudah dipahami oleh semua pihak yang terkait dengan pendidikan, sehingga setiap orang dapat mengimplementasikan secara tepat dan benar dalam setiap praktek pendidikan. Definisi pendidikan dalam perspektif kebijakan, kita telah memiliki rumusan formal dan operasional, sebagaimana termaksud dalam UU No. 20 Tahun 2003 tentang SISDIKNAS, yakni: Pendidikan adalah usaha sadar dan terencana untuk mewujudkan 
suasana belajar dan proses pembelajaran agar peserta didik secara aktif mengembangkan potensi dirinya untuk memiliki kekuatan spiritual keagamaan, pengendalian diri, kepribadian, kecerdasan, akhlak mulia, serta keterampilan yang diperlukan dirinya, masyarakat, bangsa dan negara.

Perkembangan teknologi yang berkembang saat ini memberikan dampak yang besar bagi kehidupan manusia, salah satunya adalah dampak pada perkembangan media pembelajaran. Penggunaan media pembelajaran dalam dunia pendidikan lebih banyak memberikan terobosan baru dalam meningkatkan efisiensi dan efektivitas pada proses pembelajaran. Pembelajaran konvensional, dimana guru hanya menyampaikan pembelajaran dan siswa memperhatikan sudah dianggap tidak relevan lagi digunakan pada era yang serba maju ini. Sebagai seorang guru yang memiliki tugas untuk memberikan pembelajaran kepada murid berupa ilmu pengetahuan yang dapat mereka manfaatkan dimasa depan. Bukan hanya mengembangkan ilmu pengetahuan yang dimiliki, namun juga mengembangkan proses pembelajaran yang menarik dan menambah keinginan siswa dalam belajar.

Sekolah Menengah Kejuruan (SMK) merupakan salah satu lembaga pendidikan kejuruan yang mempunyai tugas untuk mempersiapkan peserta didiknya setelah lulus agar dapat bekerja langsung sesuai bidang-bidang tertentu sesuai jurusan yang dipilih. Saputra (2015:63), menyatakan dalam proses pembelajarannya, SMK dilengkapi dengan ilmu teori dan juga peserta didik dibekali melalui praktek sehingga dalam perkembangannya SMK harus mampu menciptakan lapangan pekerjaan dan sumber daya manusia (SDM) yang berkompeten dan dapat mengikuti kemajuan ilmu pengetahuan dan teknologi. SMK merupakan salah satu penyelenggara pendidikan yang mencetak tenaga kerja yang siap pakai sesuai kompetensi program keahlian mereka masing-masing. Seiring dengan tujuan SMK dalam mewujudkan tujuan nasional, masih banyak masalah yang dihadapi, salah satunya adalah masalah efektifitas pendidikan.

Masalah efektifitas pendidikan adalah masalah yang berhubungan antara hasil dan pendidikan dengan tujuan atau sasaran pendidikan yang diharapkan. Dari hal itulah telah diusahakan berbagai cara untuk mengatasi hal tersebut yang mencangkup semua komponen pendidikan meliputi pembaharuan kurikulum, proses belajar mengajar, peningkatan kualitas guru, pengadaan buku pembelajaran, sarana dan prasarana penunjang pembelajaran, penyempurnaan sistem penilaian dan usaha-usaha dengan peningkatan kualitas pendidikan salah satunya mengimplementasikan kurikulum.

Mutu pendidikan dapat terwujud jika proses pembelajaran diselenggarakan secara efektif, artinya proses pembelajaran dapat berjalan lancar, terarah dan sesuai dengan tujuan pembelajaran. Banyak yang mempengaruhi proses pembelajaran tersebut, baik dari peserta didik maupun faktor-faktor lain seperti pendidik/guru, fasilitas lingkungan serta media yang digunakan. Siswa yang aktif dan kreatif didukung fasilitas serta guru yang menguasai materi pelajaran dan strategi penyampaian yang efektif akan menambah kualitas pembelajaran. Namun demikian untuk mencapai hasil maksimal tersebut banyak faktor yang masih menjadi kendala.

Salah satu inovasi terhadap proses pembelajaran adalah dengan menggunakan media pembelajaran pada saat menjelaskan materi dan membantu siswa dalam menyerap materi pembelajaran yang disampaikan oleh guru. Dengan menggunakan media pembelajaran, maka suatu materi abstrak akan dapat lebih mudah dimengerti oleh siswa dan media pembelajaran tersebut dikemas sedimikian rupa agar dapat menggugah keinginan siswa untuk belajar. Media pembelajaran yang digunakan dapat berupa simulator, alat peraga, komputer, CD interaktif dan lain-lain. Media pembelajaran disesuaikan dengan sifat-sifat dari mata pelajaran yang akan diaplikasikan, apabila mata pelajaran tersebut memang tidak memerlukan media pembelajaran, maka tidak perlu dibuatkan media pembelajaran. Namun, apabila mata pelajaran tersebut memerlukan pemahaman dengan dipandu dengan benar, maka media pembelajaran sangat dibutuhkan. 
Permasalahan yang dihadapi menurut hasil observasi dan wawancara dengan guru mata pelajaran Dasar Listrik dan Elektronika di SMK N 3 Singaraja yaitu: pengetahuan dan pemahaman siswa X TAV2 tentang multimeter masih kurang maksimal sehingga proses pembelajaran jadi kurang maksimal. Kurangnya pemahaman siswa tentang multimeter tersebut kemungkinan dipengaruhi semangat siswa yang kurang maksimal dalam pembelajaran multimeter. Semangat siswa yang kurang maksimal di pengaruhi oleh metode pembelajaran yang kurang menarik, dimana guru hanya menggunakan metode pembelajaran ceramah dan menggunakan media powerpoint saja. Variasi media pembelajaran yang digunakan guru masih sangat terbatas. Di jurusan TAV belum ada media pembelajaran yang mendukung materi multimeter dalam pembelajaran Dasar Listrik dan Elektronika. Untuk mengatasi hal tersebut guru harus mampu membuat semangat siswa dalam belajar lebih maksimal salah satunya menggunakan media pembelajaran yang dapat membangkitkan minat dan semangat belajar siswa.

Pada kelas X TAV2 di SMK Negeri 3 Singaraja pada mata pelajaran Dasar Listrik dan Elektronika, siswa akan diberikan pemahaman berupa materi tentang multimeter untuk menunjang dalam pembelajaran Dasar Listrik dan Elektronika. SMK Negeri 3 Singaraja dipilih sebagai tempat penelitian karena selama ini di SMK Negeri 3 Singaraja khususnya jurusan TAV belum ada media pembelajaran yang mendukung materi dalam pembelajaran Dasar Listrik dan Elektronika.

Berdasakan latar belakang yang telah dikemukakan, maka dikembangkan media pembelajaran multimeter berbasis CD interaktif pada mata pelajaran Dasar Listrik dan Elektronika di SMK Negeri 3 Singaraja. Berdasarkan identifikasi masalah, maka didapatkan batasan masalah sebagai berikut. 1) Dalam memberikan materi pelajaran guru hanya menggunakan metode pembelajaran ceramah dan menggunakan media powerpoint saja.. 2) Variasi media pembelajaran yang digunakan guru masih sangat terbatas. 3) Belum ada media pembelajaran yang mendukung materi multimeter dalam pembelajaran Dasar Listrik dan Elektronika.

Berdasarkan batassan masalah yang disebutkan di atas, maka peneliti mengambil pokok masalah seperti berikut. 1) Apakah media pembelajaran multimeter berbasis CD interaktif layak digunakan sebagai media pembelajaran pada mata pelajaran Dasar Listrik dan Elektronika di SMK Negeri 3 Singaraja? 2) Bagaimanakah respon siswa setelah menggunakan media pembelajaran multimeter berbasis CD interaktif pada mata pelajaran Dasar Listrik dan Elektronika di SMK Negeri 3 Singaraja?

Bertitik tolak dari perumusan masalah, maka tujuan penelitian ini sebagai berikut. 1) Mengetahui tingkat kelayakan media pembelajaran multimeter berbasis CD interaktif untuk digunakan sebagai media pembelajaran pada mata pelajaran Dasar Listrik dan Elektronika di SMK Negeri 3 Singaraja. 2) Mengetahui respon siswa setelah menggunakan media pembelajaran multimeter berbasis CD interaktif pada mata pelajaran Dasar Listrik dan Elektronika di SMK Negeri 3 Singaraja.

\section{Metode}

Dari rumusan masalah dan tujuan penelitian penelitian yang telah dipaparkan dengan judul penelitian Pengembangan Media Pembelajaran Multimeter berbasis CD Interaktif pada mata pelajaran Dasar Listrik dan Elektronika di SMK Negeri 3 Singaraja merupakan penelitian pengembangan (research and development yaitu metode penelitian yang digunakan untuk menghasilkan produk tertentu dan menguji keefektifan produk tersebut menurut Sugiyono (dalam Herlambang, 2018:32). Sedangkan menurut Borg dan Gall (dalam Arsa, 2017) penelitian pengembangan adalah penelitian yang beorientasi untuk mengembangkan dan validasi produk-produk dalam pendidikan. Berdasarkan teori tersebut, maka dapat disimpulkan bahwa penelitian ini termasuk Research and Development ( $R$ \& D) karena diterapkan pada mata pelajaran Dasar listrik dan Elektronika yang berupa suatu media/produk untuk mengatasi permasalahan pembelajaran di kelas X TAV SMK Negeri 3 Singaraja. 
Pada penelitian ini menggunakan model pengembangan, menurut Sugiyono (dalam Herlambang 2018:32) ada 10 langkah-langkah dalam penelitian R \& D. Dalam penelitian ini, langkah-langkah yang dikemukakan oleh Sugiyono tidak digunakan keseluruhan. Karena penelitian ini hanyalah penelitian terbatas dan tidak untuk produksi masal. Dan produk yang dihasilkan hanyalah produk awal. Pada penelitian ini menggunakan model pengembangan sugiyono, menurut sugiyono (2011: 409), ada 10 langkah - langkah dalam penelitian R\&Danatar lain: (1) Potensi dan Masalah, (2) Pengumpulan Data, (3) Desain Produk, (4) Validasi Desain, (5) Revisi Desain, (6) Uji coba produk, (7) Revisi Produk, (8) Uji Coba Pemakaian, (9) Revisi Produk, (10) Produksi Masal.

Dalam penelitian ini, peneliti menguji produk pada subjek penelitian yaitu siswa kelas X TAV karena siswa kelas $X$ mendapatkan mata pelajaran dasar elektronika. Pada prinsipnya meneliti adalah melakukan pengukuran terhadap fenomena sosial maupun alam. Meneliti dengan data yang sudah ada lebih tepat kalau dinamakan membuat laporan dari pada melakukan penelitian. Namun demikian dalam skala yang paling rendah laporan juga dapat dinyatakan sebagai bentuk penelitian Emory (dalam Sugiyono, 2009:102). Karena prinsipnya meneliti adalah suatu pengukuran, maka harus ada alat ukur yang baik. Alat ukur dalam penelitian biasanya dinamakan instrumen penelitian. Jadi instrumen penelitianadalah suatu alat yang digunakan mengukur fenomena alam maupun sosial yang diamati (Sugiyono, 2009:102).

Dalam penelitian ini, instrumen yang digunakan adalah lembar uji coba kelayakan oleh validator media, lembar uji kelayakan oleh validator materi dan lembar angket/kuisioner untuk siswa. Untuk mengukur tingkat kelayakan media ini menggunakan pengukuran skala Linkert. Menurut Sugiyono (2009 : 93), dengan menggunakan skala Linkert, maka variabel yang akan di ukur dijabarkan menjadi indikator variabel, kemudian indikator tersebut dijadikan sebagai titik tolak untuk menyusun item-item berupa pertanyaan atau pernyataan. Dalam penyusunan pernyataan dalam angket berpedoman pada variabel penilaian yang dijabarkan dalam beberapa butir soal, berupa pernyataan objektif dan bersifat positif sehingga respounden tinggal memberikan tanda centang $(\sqrt{ })$ pada salah satu jawaban yang dianggap sesuai. Angket ini disusun menggunakan model skala Linkert yang menggunakan lima alternatif pilihan jawaban. Tujuan instrumen dibuat adalah untuk mengetahui tingkat kelayakan dari media pembelajaran yang dibuat.

Metode pengumpulan data Perancangan yang disusun dalam penelitian ini adalah sebagai berikut. (1) Data Validasi Ahli diperoleh dari lembar validasi yang diberikan kepada para ahli media dan materi untuk menilai dan menelaah media pembelajaran yang dikembangkan. Hasil telah digunakan sebagai masukan untuk merevisi/ menyempurnakan media pembelajaran interaktif yang digunakan. (2) Data Respon siswa, Untuk pengumpulan data dari respon siswa mengenai media pembelajaran interaktif yang di kembangkan dilakukan dengan metode kuisioner.

Instrument penelitian atau alat yang digunakan untuk mengumpulkan data dalam suatu penelitian. 1) Lembar validasi media pembelajaran, Instrumen ini digunakan untuk mendapatkan data mengenai penilaian validator media dan validator materi terhadap media pembelajaran dikembangkan sehingga menjadi acuan/pedoman dalam merevisi media pembelajaran yang dikembangkan, yaitu instrumen uji kelayakan untuk validator materi dan instrumen uji kelayakan untuk validator media. 2) Lembar angket respon siswa, instrumen ini disusun untuk mendapatkan data mengenai pendapat siswa terhadap materi dan media pembelajaran yang dikembangkan.

Penelitian ini menggunakan teknik analisa data statistik deskriptif persentase dan jenis data yang digunakan adalah data kuantitatif. Menurut Sugiyono (2009:147), statistik deskriptif adalah statistik yang digunakan untuk menganalisis data dengan cara mendeskripsikan atau menggambarkan data yang terkumpul sebagaimana adanya tanpa bermaksud membuat kesimpulan yang berlaku untuk umum atau generalisasi.

Data penelitian kuantitatif diperoleh berupa angka-angka yang akan di olah menggunakan rumus statistik yang kemudian dihitung secara manual atau menggunakan komputer. Dalam penelitian ini, data didapat dari instrumen yang diisi oleh validator dan instrumen angket siswa yang diisi oleh siswa. Lembar validasi yang pertama adalah lembar validasi media yg diisi oleh ahli media (Kepala Program Keahlian TAV), yang kedua adalah 
lembar validasi isi yang diisi oleh ahli isi (guru) dan yang ketiga adalah lembar angket siswa yang diisi oleh siswa-siswi kelas X TAV2 di SMK Negeri 3 Singaraja. Penilaian validasi media, isi dan angket siswa dilakukan dengan kriteria sangat setuju, setuju, ragu-ragu, tidak setuju dan sangat tidak setuju. Teknik Analisa data pada penelitian ini adalah dilakukan dengan analisis menggunakan teknik deskriptif presentase serta jenis data yang digunakan dalam penelitian ini adalah data kuantitatif. Dalam penilaian validasi media dilakukan dengan beberapa ktriteria yaitu sangat setuju, setuju, kurang setuju, tidak setuju, dan sangat tidak setuju. Dimana masing-masing item memiliki skor. Rentang persentase dan kriteria kualitatif uji kelayakan media dapat ditetapkan pada Tabel.

Tabel 1. Kualifikasi tingkat kelayakan berdasarkan presentase (Sumber: Sugiyono dalam Herlambang, 2018:37)

\begin{tabular}{ccc}
\hline No & Interval & Kriteria \\
\hline 1 & $84.01 \%-100 \%$ & Sangat Layak \\
2 & $68.01 \%-84.00 \%$ & Layak \\
3 & $52.01 \%-68.00 \%$ & Cukup Layak \\
4 & $36.01 \%-52.00 \%$ & Kurang Layak \\
5 & $20.00 \%-36.00 \%$ & Tidak Layak \\
\hline
\end{tabular}

\section{Hasil dan Pembahasan}

Pengembangan media pembelajaran multimeter berbasis CD interaktif dilaksanakan uji tingkat kelayakan terhadap media yang di uji oleh validator media dan validator materi. Untuk validator media dari media pembelajaran yaitu Kepala Program Kehlian TAV di SMK N 3 Singaraja I Wayan Adi Perbawa, S.Pd. M.Pd. Untuk uji tingkat kelayakan materi di uji oleh guru mata pelajaran keterampilan yang mengajar di kelas X TAV yaitu Luh Dita Widyastuti, S.Pd.

Penelitian ini merupakan penelitian yang dilakukan untuk 1) Untuk membuat media pembelajaran multimeter berbasis CD interaktif pada mata pelajaran Dasar Listrik dan Elektronika di SMK Negeri 3 Singaraja, 2) mengetahui apakah Media Pembelajaran multimeter berbasis CD interaktif layak digunakan sebagai media pembantu dalam proses pembelajaran Dasar Listrik dan Elektronika di SMK Negeri 3 Singaraja, 3) mengetahui bagaimana respon siswa. Karena penelitian ini merupakan penelitian yang terbatas hanya mencari kelayakan dan respon maka produk yang dihasilkan tidak untuk di produksi masal.

Setelah permasalahan dan pengumpulan data di lakukan, selanjutnya dilakukan tahap desain produk. produk yang di hasilkan yaitu berupa media pembelajaran multimeter berbasis CD interaktif pada mata pelajaran dasar listrik dan elektronika di SMK N 3 singaraja. Desain ini dibuat dengan menggunakan aplikasi autoplay. desain produk atau media pembelajaran ini sebagai berikut.

1) Halaman depan. Halaman depan pada media pembelajaran ini berisi judul materi utama yang akan di bahas di media ini yaitu "PEMBELAJARAN MULTIMETER". Judul tersebut di tayangkan agar siswa mengetahui apa yang akan di bahas dan juga menarik siswa untuk mempelajarinya. 
2) Halaman menu/home. Halaman menu ini terdiri dari judul media, dan tombol-tombol menu (home, petunjuk, materi, video dan profil) serta tombol music yang berfungsi untuk on/off music di media.

3) Petunjuk Penggunaan. Petunjuk penggunaan media ini disusun untuk memandu siswa atau pengoperasi tentang cara pengguanaan media dan fungsi navigasi yang disertakan dalam media ini.

4) Halaman sub menu materi. Pada halaman ini di cantumkan sub materi yang akan di bahas, dimana akan memudahkan pengoperasi menentukan materi apa yang akan di baca. Sub menu tersebut di sertakan navigasi yang akan mengarahkan ke materi tujuan jika navigasi itu di tekan. Pada halaman materi yang dituju terdapat materi teks yang di sertai gambar dan penjelasnnya.

5) Halaman video. Pada halaman ini terdapat beberapa sub video yang membahas tentang multimeter. Dalam sub video akan di jelaskan materi dengan video dan suara. Video yang digunakan merupakan video yang dibuat oleh peneliti untuk meningkatkan keaslian media.

6) Profil. Pada halaman ini akan memperkenalkan info pembuat media pembelajaran.

7) Halaman kuis. Pada halaman kuis memuat pertanyaan yang bertujuan untuk menilai pemahaman peserta didik setelah menggunakan media pembelejaran ini.

Berdasarkan komentar dan saran yang diberikan terhadap angket pada saat uji kelayakan oleh validator media dan validator materi, sebelum dilakukan uji pemakaian atau uji lapangan. Media dilakukan revisi sesuai komentar dan saran yang diberikan para validator dan juga dari saran dosen pembimbing.

Saran yang di berikan oleh validator media adalah sebagai berikut.

1) Menyesuaikan tulisan dengan latar belakang agar lebih jelas.

2) Menambahkan keterangan penggunaan navigasi pada halaman petunjuk.

3) Memperbaiki resolusi gambar pada media agar lebih jelas dengan cara mengganti gambar dengan yang memiliki resolusi yang lebih baik

Hasil uji tingkat kelayakan media pembelajaran dari validator media mendapatkan persentase $95,71 \%$ dengan kualifikasi sangat (Tabel 4.1), sedangkan untuk persentase kelayakan dari validator materi mendapatkan persentase $98,57 \%$ termasuk dengan kualifikasi sangat layak (Tabel 4.2).

Maka hasil uji kelayakan media pembelajaran dari kedua validator, media pembelajaran multimeter berbasis CD interaktif pada mata pelajaran Dasar Listrik dan Elektronika dinyatakan dalam kualifikasi sangat layak dan dapat di pergunakan untuk proses penelitian lebih lanjut yaitu uji coba pada kelompok kecil. Pada tahap uji coba produk dalam kelompok kecil menggunakan responden 5 siswa didapatkan rerata persentase $89,07 \%$ dengan kualifikasi sangat baik (Tabel 4.4), sehingga di lanjutkan dengan uji coba kelompok besar yang terdiri dari 33 responden. Hasil dari uji coba dalam kelompok besar yaitu dengan rerata persentase 92,93\% termasuk kualifikasi sangat baik (Tabel 4.6).

Berdasarkan hasil yang didapatkan dari validator media, validator materi, uji coba dalam kelompok kecil dan uji coba pada kelompok besar membuktikan bahwa media pembelajaran multimeter berbasis $C D$ interaktif pada mata pelajaran Dasar Listrik dan Elektronika layak digunakan sebagai media pembelajaran dalam kegiatan pembelajaran pada mata pelajaran Dasar Listrik dan Elektronika untuk kelas X TAV 2 di SMK Negeri 3 Singaraja. 
Tabel 2. Hasil Penelitian

\begin{tabular}{ccc}
\hline Penguujian Produk & Persentase & Kriteria \\
\hline Uji kelayakan validator media & $95,71 \%$ & Sangat layak \\
Uji kelayakan validator materi & $98,57 \%$ & Sangat layak \\
Ujicoba kelompok kecil & $89,07 \%$ & Sangat baik \\
\hline Ujicoba kelompok besar & $92,93 \%$ & Sangat baik \\
\hline
\end{tabular}

\section{Simpulan dan Saran}

Berdasarkan hasil dan pembahasan dapat disimpulkan bahwa media pembelajaran multimeter berbasis CD interaktif dapat di operasikan dan layak digunakan sebagai media pembelajaran di kelas X TAV 2 pada mata pelajaran Dasar Listrik dan Elektronika di SMK Negeri 3 Singaraja. Hasil uji tingkat kelayakan oleh validator media mendapatkan persentase $95,71 \%$ dinyatakan dalam kualifikasi sangat layak. Hasil uji tingkat kelayakan oleh validator materi mendapatkan persentase $98,57 \%$ dinyatakan dalam kualifikasi sangat layak. Hasil uji coba dalam kelompok kecil mendapatkan rerata persentase $89,07 \%$ dengan kualifikasi sangat baik. Hasil uji coba dalam kelompok besar di peroleh rerata presentase $92,93 \%$ dengan kualifikasi sangat baik.

Adapun saran yang di sampaikan yang berkaitan dengan penelitian pengembangan media pembelajaran multimeter berbasis CD interaktif pada mata pelajaran Dasar Listrik dan Elektronika yaitu sebagai berikut. 1) Saran untuk siswa adalah agar menggunakan media pembelajaran multimeter berbasis CD interaktif pada mata pelajaran Dasar Listrik dan Elektronika sebagai media pendukung dalam pembelajaran. 2) Saran bagi guru adalah media pemebelajaran multimeter berbasis CD interaktif agar di terapkan lebih lanjut dalam proses pembelajaran di kelas sehingga dapat mencapai tujuan pembelajaran efektif dan efisien. 3) Saran bagi kelapa sekolah adalah mengelola media pembelajaran multimeter berbasis CD interaktif pada mata pelajaran Dasar Listrik dan Elektronika ini dengan baik, sebagai salah satu koleksi media pembelajaran yang dapat di manfaatkan oleh guru dan siswa. 4) Saran untuk peneliti lain adalah untuk pengembangan media pembelajaran multimeter berbasis CD interaktif mata pelajaran Dasar Listrik dan Elektronika nantinya agar menambahkan animasi sebagai simulasi pengoperasian multimeter yang peneliti sekarang belum bisa untuk mengembangkan karena keterbatasan waktu.

\section{Daftar Pustaka}

Alfin, Moch. 2015. Perbandingan Media Pembelajaran (Autoplay Media Studio) Sebagai Alat Bantu Pembelajaran Memperbaiki Cd Player Siswa Kelas Xi Di Smk Negeri 3 Surabaya.

Arsa, I Putu Suka dan Agus Adiarta. 2017. Pengembangan Bahan Ajar Berbasis Multimedia berorientasi Pemerdayaan Karakteristik Siswa Sekolah Menengah Pertama (SMP) di Jembrana. Denpasar: Seminar Nasional Vokasi dan Teknologi. 2542-2361 
Arsyad, Azhar.2014. Media pembelajaran. Jakarta: PT Raja Grafindo Persada

Dewi, NI Luh Paramitha. 2018. Pengembangan Media Pembelajaran Berbasis Multimedia Interaktif Autoplay Untuk Materi Pengenalan Komponen Elektronika Pada Siswa Kelas $X$ Tav Di Smk Negeri 3 Singaraja. Fakultas Teknik dan Kejuruan, Universitas Pendidikan Ganesha

Fitria Krisna Saputra, Sigit Yatmono. 2015. Pengembangan media pembelajaran interaktif pengenalan komponen elektronika berbasis adobe director di SMK

Herlambang, Made Dony. 2018. Pengembangan Simulasi pembangkit listrik energy terbaharukan sebagai media pembelajaran prakarya dan kewirausahaan kelas XIMIA SMA N 4 Singaraja

Hernawati, Kuswari. 2010. Modul Pelatihan Autoplay Media Studio. Yogyakarta: Universitas Negeri Yogyakarta.

Hujair, Sanaki,Ah. 2013. Media Pembelajaran Interaktif-Inovatif. Yogyakarta: Kaukaba Dipantara

Mahnu, Nunu. 2012. Media Pembelajaran. Jurnal Pemikiran Islam; Vol.37.

Musfiqon, 2012. Pengembangan Media dan Sumber Pembelajaran, Jakarta: PT Prestasi Pustakaraya

Ngarti, Jero Gede. 2018. Pengembangan media pembelajaran berbasis camtasia studio video cd interaktif mata pelajaran "menggabungkan audio ke dalam sajian multimedia" kelas xi multimedia di SMKN 2 Kintamani.

Pratama, I Gede Eka Yoga. 2018. Pengembangan Media Pembelajaran Berbasis CD Interaktif pada mata pelajaran gambar teknik kelas X TITL di Smk Negeri 3 Singaraja.

Rahmawan, Arif Budi. 2015. Pengembangan media pembelajaran kincir angin pada mata pelejaran prakarya dan kewirausahaan di smk ma'arif salam

Sugiyono, 2009. Metode Penelitian Kualitatif, Kuantitatif dan R\&D. Bandung: Alfabeta Sugiyono, 2011. Metode Penelitian Kualitatif, Kuantitatif dan R\&D. Bandung: Alfabeta Sugiyono, 2015. Metode Penelitian Kualitatif, Kuantitatif dan R\&D. Bandung: Alfabeta Sunarto. 1998. Peralatan-Workshop.pdf. Jakarta: YBØUSJ

Waluyanti, Sri. 2008. Alat-Alat Ukur dan Teknik Pengukuran. Jakarta: Direktorat Pembinaan Sekolah Menengah Kejuruan.

Wandani, Nindy Mustika. 2017. Pengembangan Multimedia Interaktif Dengan Autoplay Media studio Pada Materi Kedudukan Relatif Dua Lingkaran.

Yasa, Kadek Aditya Pradipta. 2017. Pengembangan Media pembelajaran Interaktif Berbasis Adobe Flash pada Mata Pelajaran Prakarya dan Kewirausahaan Materi Elektro(Listrik) untuk Siswa Kelas XI MIPA dan IPS di SMA Negeri 3 Singaraja. Fakultas Teknik dan Kejuruan, Universitas Pendidikan Ganesha.

Yuniastuti, dkk. 2014. Pengembangan Media Pembelajaran Cd Interaktif Sebagai Media Pembelajaran Pkn Materi Warga Negara Dan Pewarganegaraan Kelas X Di Man 3 Malang Kota Malang 
Jurnal Pendidikan Teknik Elektro Undiksha

Vol. 8 No. 2, Agustus 2018

ISSN: 2599-1531

AECT (Association for Educational Communication and Technology). Evaluating Media Programs District and School, Washington, D.C: The Association, 1976.

Undang Undang Republik Indonesia nomor 18 tahun 2002 UU No. 20 Tahun 2003 tentang SISDIKNAS 